\title{
Sciendo
}

Administration, vol. 68, no. 3 (2020), pp. 23-44

doi: 10.2478/admin-2020-0014

\section{A review of citizen engagement in our public service}

\author{
Maura Adshead \\ University of Limerick, Ireland \\ Richard Boyle \\ Institute of Public Administration, Ireland \\ Anne Colgan \\ Centre for Effective Services, Ireland
}

\section{Introduction}

The Reform and Delivery Office (RDO) in the Department of Public Expenditure and Reform has developed a series of case studies on citizen engagement, in partnership with researchers and public bodies, as a commitment under the Our Public Service 2020 development and innovation framework.

The key objectives of this initiative are to:

- document and capture learning around implementation and delivery of citizen engagement initiatives;

- acknowledge progress made and share best practice in citizen engagement initiatives; and

- create valuable educational resources that add to the existing body of knowledge on the Irish public service.

These case studies are not intended to be evaluations of the overall success and impact of the cases examined; rather, the aim is to capture 
reflections on citizen engagement initiatives. Furthermore, by telling the story behind these case studies, it is hoped to communicate achievements and lessons learned and to acknowledge the significant progress that has been made under Action 4 of Our Public Service - to significantly improve communications and engagement with the public.

The case studies initiative builds on the pilot case studies project that was undertaken by the RDO in 2017. The pilot project was established to produce teaching resources for lecturers and students of public policy and public administration, as well as for those broadly interested in public policy and its implementation. The initiative is intended to encourage learning among students and practitioners of public policy and also to inform the design and implementation process of future policy.

Four case studies on citizen engagement have been undertaken by the RDO, in collaboration with the following public bodies and research institutions:

- Comhairle na nÓg and Ireland's National Strategy on Children and Young People's Participation in Decision-Making 2015-2020 Department of Children and Youth Affairs in collaboration with the University of Limerick;

- ‘ $€ 300 \mathrm{k}$ Have Your Say' - South Dublin County Council in collaboration with the Institute of Public Administration (IPA);

- Public participation networks (PPNs) - Department of Rural and Community Development in collaboration with the Centre for Effective Services;

- Basic Payment Scheme 100 per cent online 'roadshows' Department of Agriculture, Food and the Marine in collaboration with the IPA.

The individual case studies are all available on the Our Public Service 2020 website. ${ }^{1}$ This paper is designed to appeal to two main audiences - those with a particular academic interest in the subject of citizen engagement and those more broadly interested in the implementation lessons drawn through the case studies. The literature on citizen engagement is outlined and the case studies are considered in the context of a spectrum of citizen engagement and through the lens of citizen engagement themes: strengthening democracy, ${ }^{1}$ https://www.ops2020.gov.ie/news/citizen-engagement-in-our-public-service-casestudies-june-2020/ 
demonstrating impact and providing accountability. Each of the case studies followed an agreed format designed to draw out lessons learned across all four. The background to the establishment of each citizen engagement case, implementation process, challenges encountered and lessons learned are documented in each case study. This paper considers the learning captured around implementation, which may inform the design and implementation process of future policy.

\section{Background and context}

The current overarching public service reform plan, Our Public Service 2020 (Government of Ireland, 2017), recognises the need for a public service that is resilient and responsive to the challenges Ireland faces while effectively delivering quality services to the public. A core underlying principle of meeting this commitment is to place the public at the centre of public service.

Of particular relevance here is headline Action 4, which aims to 'enhance engagement and accountability around the delivery of public services so that the public and businesses have greater input into the planning, design, implementation and review of public service' (Government of Ireland, 2017, p. 18). This action focuses on supporting public service organisations in continuing to improve engagement with the public and businesses through available structures, and in seeking new and emerging platforms.

A number of frameworks of citizen engagement can be used to assess and analyse various methods and initiatives. One of the most cited is the International Association for Public Participation (IAP2) model (IAP2, 2018; see Figure 1), which builds on Arnstein's (1969) ladder of citizen participation. The purpose of the spectrum is to demonstrate the different modes of engagement, from informing or consulting citizens to involving them in decision-making, collaborating with them and empowering them.

\section{The rationale for formal citizen engagement}

For some time now, in Ireland and elsewhere, there has been a discernible shift away from more top-down governmental structures to more inclusive, horizontal governance mechanisms (Adshead, 2006; Adshead \& Quinn, 1998; House \& McGrath, 2004). This new way of governing strives to include all relevant stakeholders in public policy 


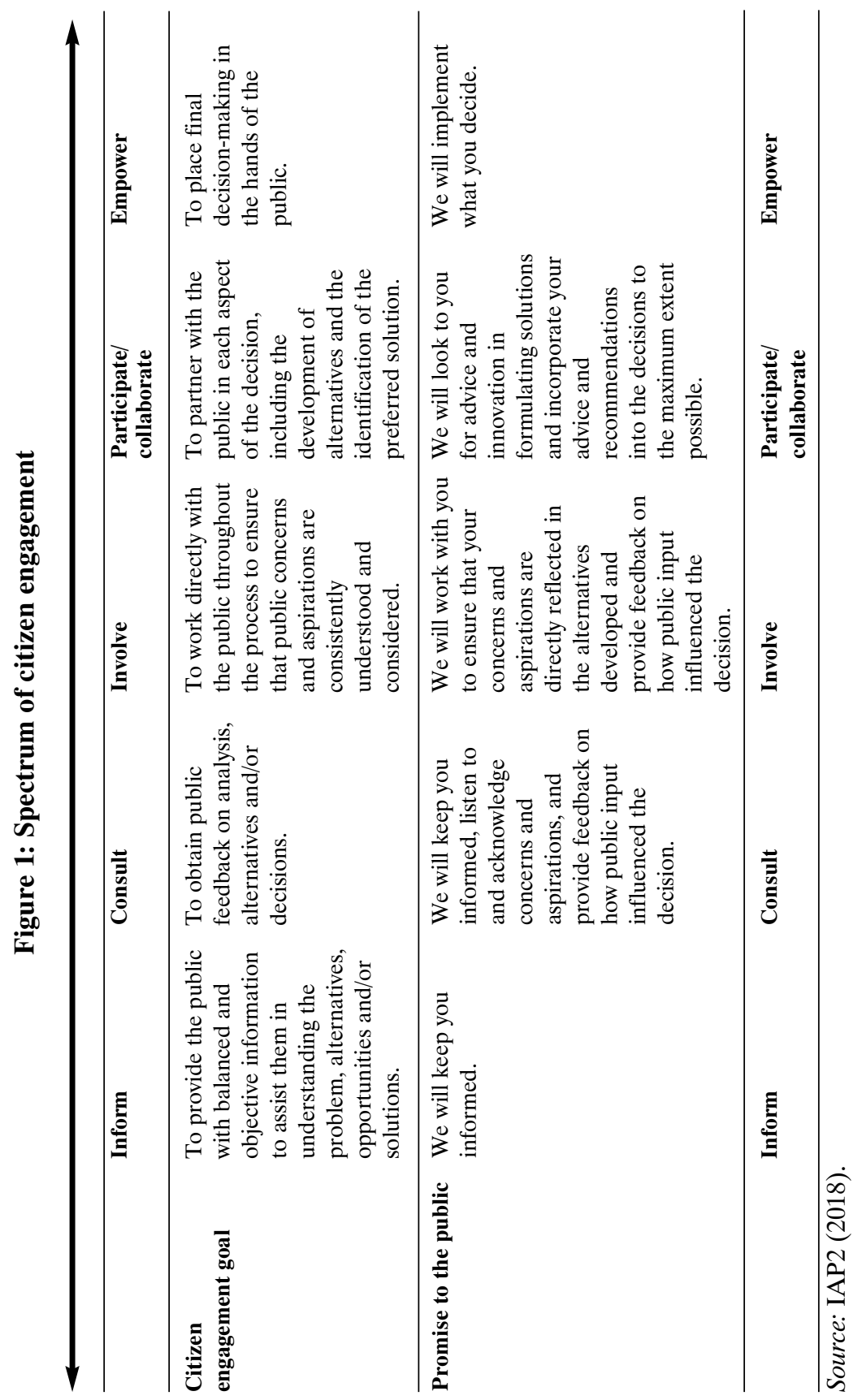


projects (Boyle \& MacCarthaigh, 2011; Elvidge, 2012; Wallace et al., 2013). In order to implement this new governance, public institutions aim to develop citizen engagement - that is, an active, intentional dialogue between citizens and public decision-makers. In some cases this approach comes from new ways of thinking about government, but in others it is driven by higher principles about best-practice policy that incorporates the rights of vulnerable citizens' voices to be heard.

Citizen engagement should be distinguished from other citizen-led participatory initiatives because it is a government-initiated, formal process, designed to improve public services, policies and programmes. Whilst government-led citizen engagement initiatives and citizen-led participation initiatives may share the same goal - both are aimed at improving public service delivery - they are initiated and implemented by different actors. Government-sponsored citizen engagement initiatives are by their nature a top-down process, implemented by public officials and designed to encourage citizens to discuss, assess and contribute to public policy objectives. Citizen-led initiatives, as the name suggests, are independent of government and organised from the bottom up. In this paper we are considering government-led citizen engagement and what can be learned from attempts to achieve it in each of our case studies.

In a fully functional democracy it is to be expected that both these types of initiatives will flourish at the same time to the mutual benefit of each. The distinction is important, however, because it alerts us to the particular responsibilities of government to develop formal governmental structures to guide the processes of citizen engagement so as to ensure that the engagement is meaningful, inclusive and influential in subsequent policy implementation.

\section{Strengthening democracy}

There is a lively and ongoing debate regarding the extent of the role for citizen engagement alongside more traditional democratic processes for the articulation and representation of opinion. These debates are most easily summarised by the distinction between aggregative and integrative democratic mechanisms. Aggregative approaches concern the formal institutions of representative government, reflecting a view of politics as a system comprised of individuals and/or interests expressing their preferences to determine 'who gets what when and how'. Integrative approaches focus more on the deliberative procedures that increase participation and produce 'democratic citizens'. 
With the acknowledged shift from government to governance, it is hard to view these different forms of democratic participation in conflict with each other. Instead, we might more usefully regard them as representing the range of participative possibilities in contemporary liberal democracy. In this context citizen engagement is a powerful democratic tool for both aggregative and integrative approaches: equipping citizens with the information to make informed choices about policy alternatives, and also developing their capacity to inform the debates that determine the policy choices in the first place. Indeed, one might even argue that experience with participative democracy (or integrative democracy) may reinforce or enhance the efficacy of representative democracy (aggregative democracy). At the very minimum, these two forms of participation should not be seen in conflict with each other or as mutually exclusive modes of participation.

The OECD (Gramberger \& Caddy, 2001, pp. 22-3) notes that there are three principle benefits to be gained from increasing governmentcitizen engagement. First, stronger government-citizen relations encourage citizens to spend time and effort on public issues, thereby strengthening the development of public policy. Second, greater trust in government is built by increasing access to information, consultation and participation opportunities: strengthening government-citizen relations enhances the legitimacy of government. Third, the stronger democracy that results from increased provision of information, consultation and participation opportunities makes government more transparent and more accountable, thereby creating the basis for more active citizenship in society. This gives government the chance to tap into wider resources of citizens and civil society in order to develop better policies and gain more trust and legitimacy.

\section{Providing accountability}

Accountability is important in evaluating the ongoing effectiveness of public officials or bodies to ensure that they are performing to their full potential, providing value for money, instilling confidence in the government and being responsive to the community. By tapping directly into the knowledge of citizens, policies are more likely to address the real needs of communities. This is particularly relevant when projects involve several actors and are too complex for the government to solve by itself. Citizen engagement can enhance citizens' sense of responsibility over projects, rendering them more willing to participate in the project implementation and/or monitoring and, in so doing, to strengthen government accountability. 
Traditionally, governments have maintained their accountability via regular recourse to public opinion, most typically in the form of competitive elections (at national and local levels) designed to provide leaders who can steer and exercise oversight. Throughout the 1990s in Ireland, as elsewhere, the advent of New Public Management approaches to government tended to augment this form of accountability and oversight by setting public policy targets and goals by which to hold politicians and policy officials accountable for their delivery (Lane, 2000). Since then a variety of exogenous (Gramberger \& Caddy, 2001) and endogenous (Government of Ireland, 2000, 2007, 2016) policy drivers have further refined this goal-setting activity with results-based planning (Wandersman et al., 2000), logic modelling (Renger \& Hurley, 2006) and impact assessment techniques (Becker, 2001) - all of which require more inclusive negotiation with stakeholders to agree on intended goals for policy outputs and outcomes.

\section{Demonstrating impact}

In the current climate of complex social challenges and constrained public spending, the need to demonstrate the impact of publicly funded services - that is, the value that they bring to society as a whole - is greater than ever before. Measuring impact is the 'holy grail' for all publicly funded initiatives and enables decision-making that is evidence-based and properly costed, as well as being cognisant of the range of ways that 'public value' may be realised (Stoker, 2006).

Public value management reflects a shift in the governmental paradigm, away from New Public Management approaches that try to treat politics like a business and towards a strong sense that the public realm is different to the commercial sector (Liddle, 2018). According to the public value approach, governing is not the same as shopping or buying and selling goods in a market economy; it is a mechanism for social coordination to achieve common purposes (Stoker, 2006, pp. 46-7). Measured under this rubric, 'public value' can only be ascertained via engagement and exchange between relevant stakeholders and government officials, who between them can determine whether or not 'public value' is delivered. In short, impact is no longer calculated solely in terms of traditional financial accounting, but according to a variety of additional public-valueoriented criteria (Department of Public Expenditure and Reform, 2012). In this context, policy impacts may touch upon other important governmental goals, such as decreasing carbon emissions, or address- 
ing mental health or other well-being targets, developing the national skills base, and so on.

\section{Citizen engagement as a means to strengthen democracy}

It has been suggested that citizen engagement augments traditional democratic practice by providing citizens with the information to make informed choices about policy alternatives; and also enhances it by developing citizens' capacity to inform the debates in a variety of deliberative and discursive fora that may help to shape the policy choices in the first place. In some cases citizen engagement enables seldom heard or vulnerable groups to participate, by giving them a voice in the policy process that they might not otherwise have. Here we look to the evidence from our case studies to examine the opportunities that citizen engagement offers to enhance citizens' capacity to contribute to democratic practice and the conditions that are necessary to underpin this kind of governmental work.

Our case studies illustrate a broad spectrum of citizen engagement initiatives, some of which are more directly concerned with advancing the capacity for citizens to have a voice in decision-making than others, which are more concerned with effective policy delivery, conveying appropriate information and ensuring that citizens are able to avail of services provided by the state. However, it is important to acknowledge that all kinds of citizen engagement offer the prospect of increasing citizen interaction with the state and, by extension, the possibility of increasing citizen confidence in the state. A fully functional democracy is premised on the trust that citizens have in government. It follows that effective citizen engagement, at any level, is an important element in supporting confidence in government.

In the remainder of this section we examine what we have learned from our case studies about the conditions necessary to underpin effective citizen engagement. These include: (i) planning for delivery, (ii) clear communications strategy, (iii) recognition of the importance of personal relationships and collaboration, and (iv) recognition of the importance of stakeholder engagement.

\section{Planning for delivery}

The Basic Payment Scheme for farmers illustrates planning for engagement over twelve months in advance, simplified systems, a focus on 'vulnerable categories', preparation of written materials in 
support of change, face-to-face support, and telephone and online assistance.

The '€300k Have Your Say' project noted that 'meticulous planning and strong governance' was a key lesson learned (Department of Public Expenditure and Reform, 2020a, p. 15). Still, it was noted that whilst a significant amount of time is needed to plan the process, this enables the initiative itself to progress quite swiftly (over a three-month period).

The PPN case study highlights the need to plan a new engagement initiative in partnership with the citizens in order to build buy-in and to ensure that local communities see the benefit of engaging in the initiative. The good news, however, is that a growing body of research evidence attests to the improved delivery of a range of governmental services consequent to citizen consultation and engagement.

The Comhairle na nÓg case noted that using children's views in the development and evaluation of healthcare service provision can have significant influence over health outcomes and reduce healthcare usage, as well as improving service delivery more generally.

\section{Importance of developing a clear communications strategy}

The Basic Payment Scheme for farmers shows that a lot of time and effort went into developing a detailed and varied communications strategy: people were told clearly what was happening, and why, and what supports were available to them, using a variety of different media - face-to-face, online, texts, letters, etc.

The Comhairle na nÓg case illustrated the significance of publishing a dedicated Comhairle na $n O$ O Toolkit, which essentially operates as a manual of well-developed guidelines for new personnel in relation to best-practice management of Comhairle groups. This, along with other initiatives such as the hosting of annual national activities, provides a calendar of events that ensures all members are communicating their activities above and beyond their own local networks.

The PPN case study pointed to the importance attached to the 'hugely foundational work of letting people know about relevant activities' and the use of a variety of mediums to do so. A communications strategy is essential in order to convey the opportunity that the engagement initiative offers for meeting the needs and wishes of citizens.

Equally, the '€ $€ 300 \mathrm{k}$ Have Your Say' project demonstrates the need for a detailed communications plan encompassing the communication 
and marketing of the initiative from start to finish. Promoting the initiative through workshops, social media and other communications was time intensive and demonstrated a skill-set requirement that is not always readily available in the public servants involved.

\section{Recognition of the importance of personal relationships}

The Basic Payment Scheme for farmers noted the importance of oneto-one meetings with farmers who had difficulty in using the online applications facility. This built good working relationships and facilitated higher levels of trust in the work the department was undertaking. In the PPN case study the creation of the role of 'resource worker', which was later augmented by a 'support worker', points to the need to resource full-time personnel dedicated to building and maintaining relationships. The study identified relationship building among key stakeholders as the foundational building block of effective engagement; time invested in relationship building provides the basis of the trust needed for effective citizen engagement.

\section{Importance of stakeholder engagement}

The PPN case noted the importance of 'mapping' the existing stakeholder presence, which was identified as a key issue to consider in order to ensure the successful integration of new organisational structures into an existing highly populated landscape of community and voluntary interests. Moreover, the study demonstrated that once these stakeholders are identified, a partnership approach to the design of new systems is vital to ensure that change is positive.

In the Comhairle na nÓg case, the importance of stakeholder involvement was a key element in building a consensus around the need for policy change in favour of children's voice, and it was noted that collaboration between government and non-government stakeholders was key to developing the first National Children's Strategy (Department of Health and Children, 2000). Once the structures have been developed, these relationships and shared commitment to the process remain important to ensure sustainability of the structure.

Equally, in the Basic Payment Scheme for farmers case, the Irish Farmers' Association (IFA), the largest farming representative organisation, was one of the bodies consulted prior to the department's launch of the engagement campaign. One particular concern of the IFA was the capacity of farmers to apply online without 
support or engaging agents to apply on their behalf. They supported the approach taken by the department in holding face-to-face clinics and they conducted their own information campaign to promote this.

\section{Citizen engagement as a means of providing accountability}

Governmental accountability is concerned with evaluating the effectiveness of citizen engagement strategies, in order to ensure that they are performing to their full potential, providing value for money, instilling confidence in the government and being responsive to the community.

\section{Providing political leadership and legitimacy for engagement}

Our case studies demonstrate that political support is necessary to both build and maintain citizen engagement. This may come in the form of active support from a key minister or departmental initiative, or from a legislative base underpinning the policy initiative.

In the Basic Payment Scheme for farmers the active support of the minister gave the project additional impetus and standing. Department staff also worked hard to reassure politicians as to the approach being taken and to the efforts being made, through the clinics in particular, to ensure that exclusion of some farmers was not an issue. This helped ensure that political support for the initiative was maintained.

In the Comhairle na nÓg case ministerial support also helped to keep children's rights to the fore on the policy agenda - a task that was aided and supported in the early years by a determined interdepartmental team of civil servants, led by the secretary general in the Department of Health. The Taoiseach's own interest in the strategy provided an additional motivational push. This political interest was concretised with the creation of the National Children's Office as a dedicated government agency responsible for carrying out the National Strategy and later reinforced by the creation of a full government department dedicated to the needs of children and young people - one where children and young people's participation was regarded as a central departmental function.

The PPN framework was supported by legislative underpinning with clear departmental responsibility, initially in the Department of the Environment, Community and Local Government and currently in the Department of Rural and Community Development. The National Advisory Committee, which represents key national and local 
stakeholders, provides leadership from across the local and national levels.

The experience of the ' $€ 300 \mathrm{k}$ Have Your Say' project demonstrated the important role that the elected council played in the project as local representatives and intermediaries for their communities. More generally, the involvement of the chief executive was seen as a crucial signifier of the status of the project. From the outset, the initiative was driven and supported by elected members, with high-level political and executive leadership and commitment being important elements in the process.

\section{Key role of a core team to plan and direct engagement strategy}

In the Basic Payment Scheme for farmers case the presence of a core team to coordinate and oversee the process provided continuity and developed internal capacity. This was also evident in the Comhairle na nÓg case, where the creation of the Children and Young People's Participation Support Service enabled a more consistent and coordinated approach to Comhairlí support and training.

This support service in turn was spearheaded by a dedicated unit with professional expertise within the department, as well as a general civil service staff complement. In addition, dedicated staff with responsibility for the operation of Comhairle na nÓg within the local authority have also been important to the successful integration of Comhairle na nÓg.

In the case of the PPN the initial impetus and design of the structure was undertaken by an expert group. The oversight, monitoring and evaluation role has been taken up by a national advisory group of key stakeholders, working with and under the auspices of the Department of Rural and Community Development.

The ' $€ 300 \mathrm{k}$ Have Your Say' initiative created a permanent steering group in 2017, designed to inclusively represent local areas and political parties, with agreed terms of reference for governance of the process.

\section{Instilling confidence in government}

As has been suggested already, there is an obvious injunction that citizen engagement should work to increase citizen confidence in government. And evidence from our case studies suggests that this is the case. Feedback from citizen engagement activities demonstrates that they offer the opportunity for citizens to experience positive interactions with governing systems. Participants in the ' $€ 300 \mathrm{k}$ Have Your Say' workshops were overwhelmingly positive. 
In acknowledging, however, that engagement is a two-way process, we might also consider how the positive experience of participating in an effective citizen engagement initiative might also increase public servants' confidence in the utility of citizen engagement in supporting efficient policy delivery. For example, the approach adopted in the PPNs around the country demonstrates the growing level of collaboration between council officials and PPNs, and the extent to which councils now draw on the PPNs as a key way of disseminating information to citizens and eliciting responses to public consultations. The Basic Payment Scheme for farmers has been adapted and applied to other areas of the department. A number of evaluations of the Comhairle na nÓg processes at the local and national level have also shown a very high level of support and value of the structures from senior decision-makers and policymakers across the political and policymaking arenas.

\section{Demonstrating responsiveness to citizens}

Citizen engagement, as the term implies, suggests a dialogue between government and citizen. For this to occur, effective engagement strategies need to incorporate plans to capture and respond to stakeholder feedback.

The PPN study notes the importance for any new citizen engagement structure to be subject to critical review, and the need to build into the plan a review mechanism in order to get a clear sense of what works and to respond to issues and challenges with fresh thinking and new approaches where necessary.

The need to ensure that citizen engagement is as inclusive as possible was flagged by the ' $€ 300 \mathrm{k}$ Have Your Say' case study, which raised the concern that new engagement initiatives do not simply provide fresh ways to consult 'the usual suspects'. In this respect, the quality of facilitation can be crucial to ensuring that all voices are heard. This case study further demonstrated the importance of citizen feedback following an engagement initiative to explain the outcomes (where necessary) and provide effective follow-up of issues raised.

The Basic Payment Scheme case study responded to a particular need for farmers who were not technologically literate or had difficulty in accessing online systems. This approach is in line with the 'assisted digital' initiatives promoted under the Our Public Service 2020 reform programme, whereby people who are not able to use digital government independently are facilitated to do so. 
The Comhairle na nÓg case demonstrates, however, that the responsiveness to citizens is often contingent on wider governmental interest in engagement. Whilst Comhairlí are able to provide the space for children and young people to voice their concerns, the extent to which decision-makers become a willing audience, subject to influence, is critically dependent on governmental structures that are external to Comhairle na nÓg.

\section{Recognising possible tension between competing frameworks for action or competing claims to represent citizens}

Tensions are not inevitable and need not be permanent. Moreover, where they do exist, they may be a useful early indicator for the challenges that lie ahead. Our case studies demonstrate that acknowledging the potential for tension is an important and necessary step in developing new systems and frameworks for action. 'This groundwork is best done early in the implementation process, to optimize the prospects for success and to minimize unnecessary tensions that may require mediation later on in the process' (Department of Public Expenditure and Reform, 2020b, p. 14).

The PPN case study, for example, illustrated the potential for tension between national and local frameworks for action, reflected in the difficult balancing act between ensuring that local participating organisations maintained their autonomy whilst ensuring that they are still able to provide an accountability mechanism. A similar tension might also be evident between the mandates of elected local council representatives vis-à-vis non-elected PPN representatives if these mandates are experienced as competing rather than collaborative or complementary.

In the Comhairle na nÓg case, potential tensions are largely averted by the clear accountability structures - in terms of governance and role definitions - that are provided to all Comhairle na nÓg coordinators, steering committee members and Comhairle members. However, it was noted that the accountability within Comhairlí structures is not always matched by a similar diligence outside Comhairlí as they interact with other local decision-making structures, and in this respect the integration of Comhairlí into some local authority decision-making structures can be less than ideal.

\section{Demonstrating the impact of citizen engagement}

In the contemporary digital era, there are multiple ways to measure impact. Ultimately, however, these all amount to exercises in counting: 
counting the number of citizens reached, counting the number of contacts made, counting the number of hits on a website. These metrics do not account for the quality of the engagement with citizens and they offer no assurance of participation from seldom heard voices. In order to acknowledge this deficit, impact is no longer calculated solely in terms of traditional financial accounting, but according to a variety of additional public-value-oriented criteria (Department of Public Expenditure and Reform, 2012).

Public value management is a mode of public management which advocates that public managers should be encouraged and empowered to create an ongoing deliberative process with citizens and consumers in order to negotiate and shape public preferences for what is valuable and what they should produce (Moore, 1995). Demonstrating the impact of citizen engagement in our case studies according to public value criteria would require a citizen-engaged and interrogative evaluation process, which is not possible to implement post facto. Still, we were able to identify elements of a public value approach in each of the case studies, highlighting the kinds of measures that can be adopted to increase public value. These include: (i) ongoing evaluations, and (ii) recognising that public value benefits have financial costs but that (iii) these costs can represent good value for money.

\section{Instituting ongoing evidence-based evaluations of engagement progress}

In the Basic Payment Scheme case a lot of effort went into using and developing data and other evidence to inform actions and track progress. The profiling of the approximately 30,000 farmers who were not using the online system in 2016 provided sound evidence of the make-up and characteristics of those farmers. Then tracking of progress with regard to how many farmers were moving online and how many remained enabled further detailed targeting of the remaining farmers.

In the Comhairle na nÓg case the introduction of evaluation criteria as part of the allocation of development funds facilitated more effective approaches to developing children's voice and these review mechanisms enabled more shared learning between Comhairlí in the annual review mechanism.

\section{Recognising that public value benefits come with traditional financial costs}

Notwithstanding the evidence of value for money, citizen engagement is not free and, as the PPN study notes, as engagement initiatives 
increase in their scope and reach, the resources needed to carry out this engagement will increase commensurately, and this incrementally growing resource investment needs to be factored into budgets.

The need for further budgetary consideration was also evident in the Comhairle na nÓg case, which demonstrated the regressive nature of a flat subvention rate $(€ 20,000)$ to all Comhairlí. Giving all Comhairlí the same subvention does not take into account the disproportionate spend on transport that many rural Comhairlí face compared to their more urban counterparts, or even the fact that some Comhairlí have larger numbers than others. Notwithstanding this disparity, the Comhairlí provide a national infrastructure for citizen engagement that is unparalleled anywhere else in Europe. Comhairlí reach a cohort that would otherwise have no voice, and represent that voice in ways that are relatively cost-effective and impactful.

The '€300k Have Your Say' initiative is regarded as a relatively resource-intensive process, requiring dedicated staff time from a number of areas of the local authority. However, the intensity of this process - around three months of workshops and engagement activities - is relatively short-lived, suggesting that the full-time staff equivalent is perhaps no more than that in other engagement initiatives that operate over a twelve-month period. Moreover, it is worth thinking more clearly about what this cost is being compared with: more traditional local authority planning processes can be long and drawn out affairs, often lengthened by objections and appeals which come with less public engagement.

\section{Value for money - What do our case studies tell us about the public value attached to their engagement?}

The ' $€ 300 \mathrm{k}$ Have Your Say' case showed that participatory budgeting works as a means of engaging citizens. While it is hard to measure or evaluate the benefits in terms of citizen engagement, feedback from workshop participants, a small online survey and interviews with those involved, including elected representatives who would be aware of their constituents' views on the initiative, suggest a very positive response to the initiative and its value. The online Basic Payment Scheme has been a major success. The target of 100 per cent online applications has been reached and the initiative was well received by farming families and stakeholder groups across the country. There is a high level of commitment to the initiative and it is widely regarded as providing public value. 
The PPN case study points to the fact that new long-term national structures such as the PPN take time to bed down in their community. It follows that measuring impact will be a long-term project; unlike the Basic Payment Scheme, where there is a measurable outcome, the impact of the PPN will only emerge over time. In the short term, success can best be measured by the extent to which the engagement processes have been embedded in the landscape.

Finally, the funding of Comhairle na nÓg enables the state to meet its responsibilities to Article 12 of the UN Convention on the Rights of the Child, which may not have an economic price tag but has value in terms of our international reputation and significant public value in terms of delivering children's rights.

\section{Lessons learned}

At the outset of this paper we presented a spectrum of citizen engagement, which ranged from informing to consulting, to involving, to collaborating and finally to empowering. As noted earlier, we do not see one end of the spectrum as being inherently better or worse: the nature of the engagement determines what type of citizen engagement is most appropriate.

In this concluding section we review the cases in the light of the original spectrum of engagement and consider the key learning that they reveal. Our intention is to derive a set of working principles that may be used to advance citizen engagement initiatives in government.

If we were to locate each of the case studies in this spectrum, the circumstances and conditions of their terms of reference would put them in different places. The Basic Payment Scheme case is a departmental initiative, focused on engaging a defined group of stakeholders to give them key relevant information and assistance necessary to access a specific and critical online funding initiative, which falls more clearly within the 'inform' and 'consult' categories.

The ' $€ 300 \mathrm{k}$ Have Your Say' case is a local authority initiative, time-bound and limited to a specific geographic area but with a broader remit for citizen engagement than the Basic Payment Scheme, thus placing it at the 'collaborate' and 'empower' end of the spectrum.

The other two case studies, PPNs and Comhairle na nÓg, bridge the divide between local and central government, being implemented at local authority level and also subject to the guidance of the relevant 
government department. In doing so, they necessarily interlink into a wider set of institutional mechanisms and permanent consultative mechanisms.

Whatever the model used, it is clear from our case studies that when it is done well, engaging citizens can improve the delivery and quality of public services, bring about greater transparency and social inclusion, and result in tangible improvements in people's lives.

Drawing on the lessons learned from across the four case studies, the following ten working principles have been identified. These principles are common to each case study, regardless of where on the spectrum of citizen engagement they may be positioned. These principles reflect the three-part rationale for citizen engagement set out at the beginning of the paper. Effective citizen engagement better informs evidence-based policy and service design through strengthening democracy, providing accountability and demonstrating impact, as follows:

- Strengthening democracy - citizen engagement supports democracy by giving citizens access to information to help them make informed choices about policy alternatives, as well as developing their capacity to contribute effectively to debates that shape policy choices. The following working principles support achieving this goal: effective planning, stakeholder engagement, clear communications, collaboration and investment in citizen capacity.

- Providing accountability - accountability is important in evaluating the ongoing effectiveness of public officials or bodies to ensure they are performing at their full potential. The following working principles support public service performance and accountability: effective leadership, the skills of the core team driving and delivering the citizen engagement initiative, clarity of purpose and collaboration.

- Demonstrating impact - using the tools, routines and processes of public governance (data, evidence, evaluations, impact assessments, reviews) to demonstrate value for money and achievement of public value for the investment in citizen engagement. The following working principles support achieving this goal: using data and evidence to measure impact and inform future policy decisions. 


\section{Working principles for effective citizen engagement}

\section{Decide on clear engagement objective}

The rationale for the citizen engagement initiative should be clearly drawn and understood by all stakeholders, from the outset. Public officials should be clear about the intended citizen engagement goal and citizens clear about the intended engagement outcome.

\section{Plan for delivery}

Citizen engagement initiatives require planning for delivery. Careful consideration should be given in advance to the design of the governance structures, roles and responsibilities of the core team, and the strategic design of the citizen engagement strategy (stakeholder engagement strategy, change management strategy, communications strategy, implementation plan, including milestones to achieve key intended outcomes).

\section{Design inclusive stakeholder engagement strategy}

The stakeholder engagement plan should aim to be as inclusive as possible. It is important that the engagement moves beyond people with a particular interest in the policy area and with the resources to engage fully in such processes, giving particular consideration on how to engage those 'harder to reach' voices.

\section{Plan clear communications strategy}

Communications strategies should clearly identify what is happening, why and what supports are available. It should also use a wide range of means to reach key stakeholder groups such as face-to-face, online, texts, letters and social media.

\section{Collaborate to build trusted relationships}

The importance of personal relationships and relationship building to developing trust should be recognised. Consideration should be given, from the outset, to addressing issues collaboratively and in a spirit of partnership to help overcome any potential obstacles and build consensus.

\section{Invest in capacity building}

Capacity-building measures, such as training and provision of guidance materials, handbooks and toolkits, are necessary to ensuring that participants are equipped with the requisite knowledge and skills to be active, rather than passive, participants in the initiative. 


\section{Demonstrate clear leadership}

Political support - ministerial, executive or supported by legislative underpinning - is critical to building and maintaining citizen engagement. Visible and committed leadership provides legitimacy and signals the importance being attached to the engagement initiative, which helps to secure citizen buy-in.

\section{Establish core team to drive engagement}

The role of the core team in the design, delivery and success of the citizen engagement initiative cannot be underestimated. The capacity and personal commitment of the officials responsible for driving the initiative are critical to its success.

\section{Use data and evidence to improve citizen outcomes}

Data and evidence provide rich sources of insight that can inform the design of the citizen engagement initiative at the outset to ensure that it is as targeted and effective as possible. It can also be used to track progress, monitor effectiveness, demonstrate public value benefit and value for money, identify good practice and share learning.

\section{Apply the lessons}

Ongoing evaluation and use of evidence in reviewing outcomes will inform continued improvement. Feedback and evaluation mechanisms should be factored into the design of the initiative throughout its lifespan. Best practice can be identified and replicated.

\section{Final reflections}

The experience gained from the four case studies, plus other academic reviews of practice, shows that engaging citizens can improve the delivery and quality of public services and bring about greater transparency, accountability and social inclusion, resulting in tangible improvements in public policy and people's lives.

Citizen engagement allows the dialogue with the public to be expanded, and can be particularly helpful in including the views and perspectives of traditionally marginalised or excluded groups. This can help strengthen public consensus for policy and service delivery reforms, and enhance the broad public ownership necessary to sustain them.

However, the achievement of these positive results requires a cultural evolution in the way public services plan for, communicate 
with and engage the public, with citizens as active agents of change rather than passive recipients. In terms of capacity building, the good practice and strong experience in managing citizen engagement initiatives that exist in some parts of government could be drawn on and shared to areas with less developed citizen engagement experience and expertise.

\section{References}

Adshead, M. (2006). New modes of governance and the Irish case: Finding evidence for explanations of social partnership. Economic and Social Review, 37 (3), 319-42.

Adshead, M., \& Quinn, B. (1998). The move from government to governance: Irish development policy's paradigm shift. Politics and Policy, 26 (2), 209-25.

Arnstein, S. R. (1969). A ladder of citizen participation. Journal of the American Planning Association, 35 (4), 216-24.

Becker, H. A. (2001). Social impact assessment. European Journal of Operational Research, 128 (2), 311-21.

Boyle, R., \& MacCarthaigh. M. (2011). Fit for purpose? Challenges for Irish public administration and priorities for public service reform. Dublin: Institute of Public Administration.

Department of Health and Children (2000). Our children - Their lives: National children's strategy, 2000-2010. Dublin: Government Publications.

Department of Public Expenditure and Reform (2012). The VFM code. Retrieved from http://vfm.per.gov.ie [28 July 2020].

Department of Public Expenditure and Reform (2020a). 300k Have your say citizen engagement case study. Dublin: Department of Public Expenditure and Reform.

Department of Public Expenditure and Reform (2020b). Public participation network case study. Dublin: Department of Public Expenditure and Reform.

Elvidge, J. (2012). The enabling state: A discussion paper. Fife: Carnegie UK Trust.

Government of Ireland (2000). White Paper on a framework for supporting voluntary activity and for developing the relationship between the state and the community and voluntary sector. Dublin: Government Publications.

Government of Ireland (2007). National development plan: Transforming Ireland. A better quality of life for all. Dublin: Government Publications.

Government of Ireland (2016). Ireland's national skills strategy 2025. Dublin: Government Publications.

Government of Ireland (2017). Our public service 2020. Dublin: Government Publications. 
Gramberger, M., \& Caddy, J. (2001). Citizens as partners: OECD handbook on information, consultation and public participation in policy making. Paris: OECD.

House, J. D., \& McGrath, K. (2004). Innovative governance and development in the new Ireland: Social partnership and the integrated approach. Governance: An International Journal of Policy, Administration and Institutions, 17 (1), 29-57.

IAP2 (2018). IAP2 spectrum of public participation. Retrieved from https://cdn.ymaws.com/www.iap2.org/resource/resmgr/pillars/Spectrum 8.5x11_Print.pdf [28 July 2020].

Lane, J. E. (2000). New public management. Abingdon: Taylor and Francis.

Liddle, J. (2018). Public value management and new public governance: Key traits, issues and developments. In E. Ongaro \& S. Van Thiel (eds), The Palgrave handbook of public administration and management in Europe. London: Palgrave Macmillan.

Moore, M. (1995). Creating public value: Strategic management in government. Massachusetts: Harvard University Press.

Renger, R., \& Hurley, C. (2006). From theory to practice: Lessons learned in the application of the ATM approach to developing logic models. Evaluation and Program Planning, 29 (2), 106-119.

Stoker, G. (2006). Public value management: A new narrative for networked governance? The American Review of Public Administration, 36, 41-57.

Wallace, J., Mathias, M., \& Brotchie, J. (2013). Weathering the storm? A look at small countries' public services in times of austerity. Fife: Carnegie UK Trust.

Wandersman, A., Imm, P., Chinman, M., \& Kaftarian, S. (2000). Getting to outcomes: A results-based approach to accountability. Evaluation and Program Planning, 23, 389-95. 